\title{
Design and Construction of a Wireless Based Electrical Appliance Control System
}

\section{OJO, KO; ODUNZE E.C}

\author{
Department of Science Laboratory Technology, University of Benin, Benin City, Nigeria \\ *Corresponding Author Email: meetengrodu@gmail.com,odunze.ebere@gmail.com;_Tel: 08037999582
}

\begin{abstract}
The wireless based electrical appliance control system puts forth a system which enables users to control home appliances using mobile phone or computer with the aid of an application device, The design makes use of an efficient and low-cost technology for controlling the appliances thus minimizing the power wastage. The interface of the mobile application is used to send signals to another device connected to an 8052 microcontroller programmed to interpret the signal from the phone and control electrical loads via relays switched with transistors, the complete system operates on a 5 volts power supply which is obtained from the public mains. The design is built for the sole purpose of efficient control of electrical appliances, part of its objectives is to embed a user friendly control interface for electrical device using internet device, and it is a fast and efficient approach to control electrical appliances. The design is a viable one in the sense that it will go a long way in helping to checkmate unnecessary wastage of voltage and making it more convenient to control electrical appliances from even a remote area.
\end{abstract}

\section{DOI: https://dx.doi.org/10.4314/jasem.v22i9.13}

Copyright: Copyright $($ C 2018 Ojo and Odunze. This is an open access article distributed under the Creative Commons Attribution License (CCL), which permits unrestricted use, distribution, and reproduction in any medium, provided the original work is properly cited.

Dates: Received: 04 April 2018; Revised: 23 July 2018; Accepted: 30 August 2018

Keywords: Wireless based electrical appliance control system, Microcontroller, Mobile Application, Electrical Appliances

This project puts forth the equipment which enables users to control their home appliances using their mobile phone or system with the aid of an application device, over the years technology has been ever evolving, and as a result, new means are being developed for easier and safer control of electrical devices for more efficient power management at homes and workplaces. The increasing technology and digitization demands for a low-cost and efficient system. This design makes use of an efficient and lowcost technology for controlling the appliances thus minimizing the power wastage. This design is built to control appliance from any location this could also be of great importance in security light control as far it is connected to the switch board Liu, Y (2013). Much of the research attention has been given in academia. Various wireless technologies that can support some form of remote data transfer, sensing and control such as Bluetooth, Wireless Fidelity (Wi-Fi), Radio Frequency Identification (RFID), and mobile networks have been utilized to embed various levels of intelligence in the home Al-Qutayri, MA; Jeedella, JS (2010). The studies by [Piyare, R; Tazil, M (2011), Ching Yuan et al., (2011), Potts, J; Sukittanon, S (2012), Ramlee et al., (2013), Yan, M; Shi, H (2013), Javale et al., (2013), and Anwaarullah, SV; Syed, A (2013)], have presented Bluetooth based home automation systems using Android Smart phones without the Internet controllability. However, due to limited range of operation (maximum up to $100 \mathrm{~m}$ ) the system is unable to cope with mobility and can only be controlled within the vicinity. Researchers have also attempted to provide network interoperability and remote access to control devices and appliances at home using home gateways. ElShafee, A; Hamed, KA (2012), Introduced a Wi-Fi based home control system using PC based web server which manages the connected home devices. Similar designs have also been presented in [(Alkar, AZ; Buhur, U (2005), Sharma, U; Reddy, SRN (2012), Liang et al., (2002) and Rajabzadeh et al., (2010)], where a dedicated web server, database and a web page have been developed to interconnect and manage the devices with the Internet.

The design is built for the sole purpose of efficient control of electrical appliances, part of its objectives is to embed a user friendly control interface for electrical device using internet device, and it is a fast and efficient approach to control electrical appliances. The design is a viable one in the sense that it will go a long way in helping to checkmate unnecessary wastage of voltage and making it more convenient to control electrical appliances from even a remote area. 


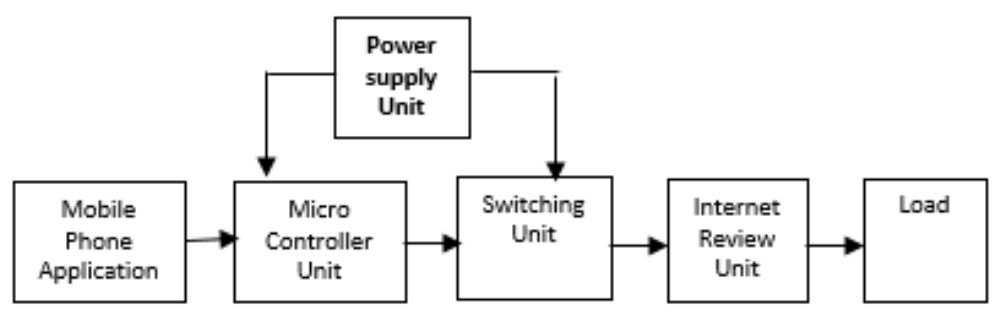

Fig. 1 Block Diagram of the design (Ensure to cite this figure in the paper)

\section{MATERIALS AND METHODS}

The wireless based electrical appliance control system complete circuitry has been analyzed here with the different modules in focus. The design was built with the following materials: Transformer, Diodes, Capacitors, Voltage regulator, Resistor, Relay, Transistor, RS-TTL converter, Crystal oscillator, Microcontroller, Vero board, Plastic casing, Connecting wires, Loads, Lamp holder. Each of them playing a vital role in the design.

Power Supply Unit: This is the circuit that supplies power to the full system. It obtains its power source from a 220voltas ac power supply source, to deliver a 5 volts dc power output. The circuit diagram is as shown in Fig 2.

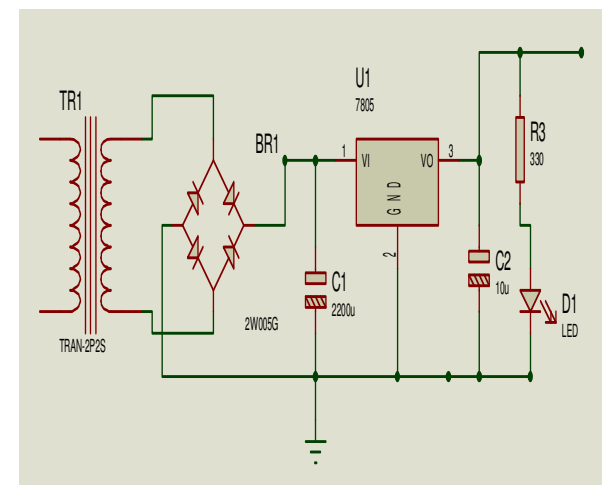

Fig 2: The Power Supply Unit

Microcontroller Unit: The microcontroller unit circuit is the heart of this project. This is where the program for the control part of the project is written and burned using assembly language and a universal programmer, respectively. The circuit diagram is as shown in Fig 3.

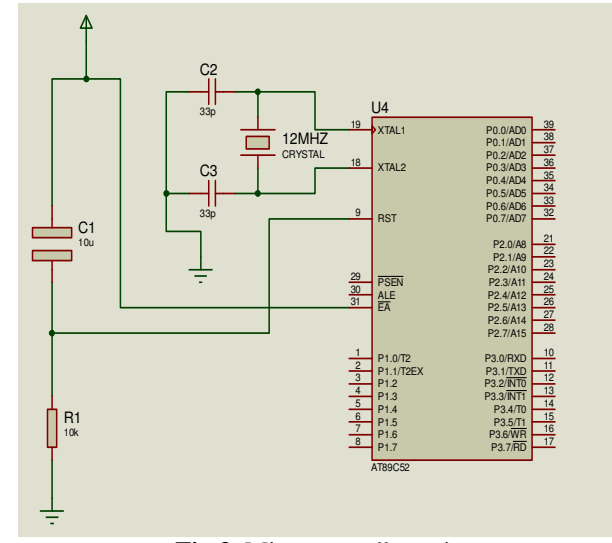

Fig 3: Microcontroller unit

The 8052 microcontroller hardware circuit is usually a very flexible one and all the surrounding components are given a recommended range of values, by the datasheet but the actual values can be chosen by the programmer.

Switching Unit: This is the unit that the system uses to control the load, it consist of switching transistor, biasing resistor, and switching relay.

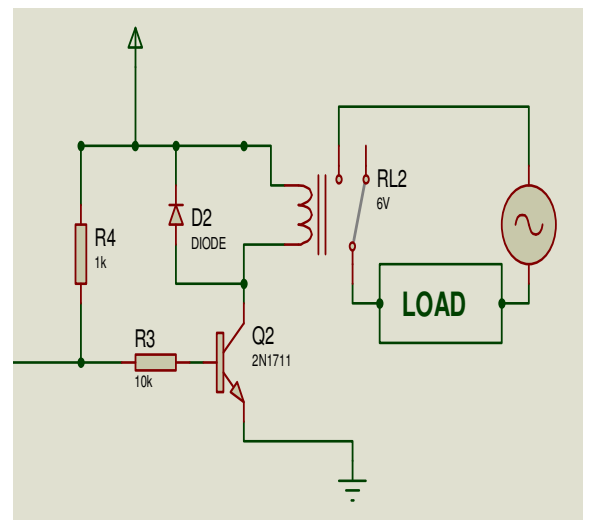

Fig 4: Switching circuit unit and load

Internet Receiver Unit: This is the unit that the system uses to receive data via the internet, for the sake of this project demonstration, the internet receiving medium 
is an internet enable phone, this phone is connected wirelessly to the circuit and the circuit uses Universal Asynchronous Receiver Transmitter (UART).

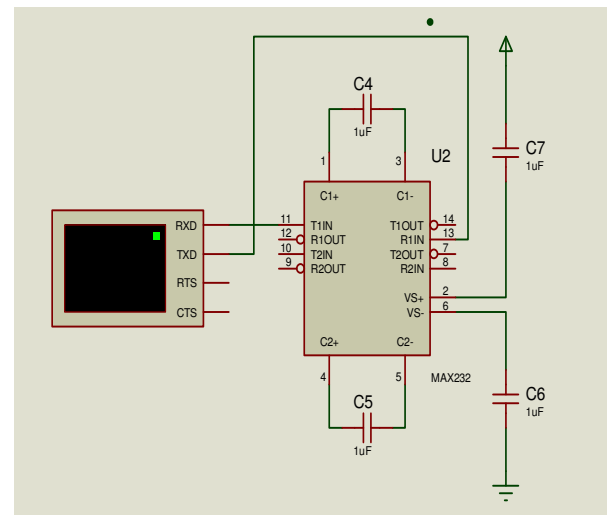

Fig 5: Internet Receiver unit

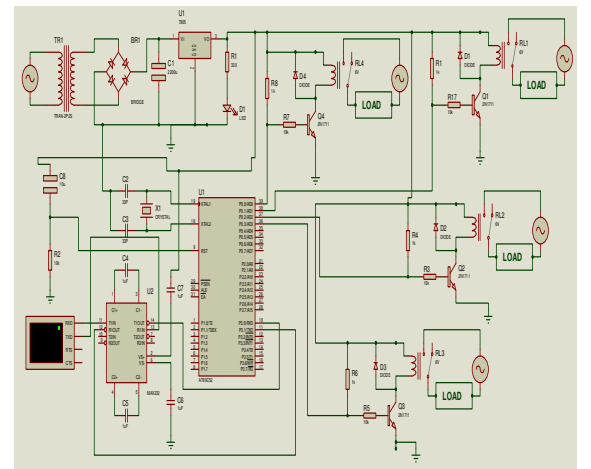

Fig 6: complete schematics of a wireless based electrical appliance control system

\section{RESULTS AND DISCUSSION}

The wireless control for electrical appliances operates using internet in such a way that a mobile application is written on an android phone, the interface of the mobile application is used to send signals to another mobile device connected to an 8052 microcontroller programmed to interpret the signal from the phone and control electrical loads via relays switched with transistors. The complete system operates on a 5 volts power supply which is obtained from the public mains. The power supply unit works in such a way that a stepdown transformer will step down the ac power source from a high one to a low one then the ac power will be rectified to pulsating dc using rectifier diodes. The ripples is filtered off using filter capacitors while a voltage regulator was used to keep the output voltage constant. Simply put, the Mode of transmission is wireless connections through a Central Controller (It is hardware interface that communicates with user interface by controlling domestic services) and Electronic devices, which is compatible with the transmission mode, and connected to the Central control system, used in testing the design. But for the purpose of this design an electric bulb was used

Conclusion: The methodology employed in the design of the wireless based electrical appliance control system is simple and easy to understand. Normally, the advancements in mobile technology and the reduction in costs have made it easier and convenient to incorporate mobile technology into electrical appliance control system. The design is a viable one in the sense that it will go a long way in helping to checkmate unnecessary wastage of voltage and making it more convenient to control electrical appliances from even a remote area.

\section{REFERENCES}

Alkar, AZ; Buhur, U (2005). An Internet based wireless home automation system for multifunctional devices, IEEE Transactions on Consumer Electronics, 51:11691174.

Al-Qutayri, MA; Jeedella, JS (2010). Integrated Wireless Technologies for Smart Homes Applications in Smart Home Systems, 1: 44-51.

Anwaarullah, SV; Syed, A (2013). RTOS based Home Automation System using Android, Inter. J. Adv. Trends in Computer Sci. Engineer. 2: 480-484,

Ching-Yuan, $\mathrm{CH}$; Shiau-Chin,W; Cheng-Min, L (2011).Bluetooth-Based Android Interactive Applications for Smart Living, in Innovations in Bioinspired Computing and Applications, 309-312.

ElShafee, A; Hamed, KA (2012). Design and Implementation of a WiFi Based Home Automation System. World Acad. Sci. Engineer. Technol. 21772180.

Javale, D; Mohsin, M; Nandanwar, S; Shingate, M (2013). Home Automation and Security System Using Android ADK, International Journal of Electronics Communication and Computer Technology, 3: 382385 .

Liang, NS; Fu, LC; and Wu, CL (2002). An integrated, flexible, and Internet-based control architecture for home automation system in the Internet era, IEEE International Conference in Robotics and Automation Proceedings, 2: 1101-1106.

Liu, Y (2013). Study on Smart Home System Based on Internet of Things Technology, in Informatics and Management Science IV, 207: 73-81.

Piyare, R; Tazil, M (2011). Bluetooth based home automation system using cell phone, IEEE15th International Symposium on consumer electronics, 192-195. 
Potts, J; Sukittanon, S (2012). Exploiting Bluetooth on Android mobile devices for home security application, in Southeastcon, Proceedings of IEEE, 1-4.

Rajabzadeh, A; Manashty AR; Jahromi, ZF (2010). A Mobile Application for Smart House Remote Control System," World Academy of Science, Engineering and Technology, 62: 80-86.

Ramlee, RA; Tang, DHZ; Ismail, MM (2012). Smart home system for Disabled People via Wireless Bluetooth, International Conference on System Engineering and Technology, 1-4.

Ramlee, RA; Leong, MH; Singh, RSS; Ismail, MM; Othman, MA; Sulaiman, HA (2013).Bluetooth Remote Home Automation System Using Android Application, The International Journal of Engineering And Science, 2: 149-153.

Shahriyar, R; Hoque, E; Sohan, S; Naim, I; Akbar, MM; Khan, MK (2008). Remote controlling of home appliances using mobile telephony, Inter. J. Smart Home, 2: 37-54.

Sharma, U; Reddy, SRN (2012). Design of Home/Office Automation Using Wireless Sensor Network, Inter. J. Computer Applications, 43: 53-60.

Yan, M; Shi, H (2013). Smart Living Using Bluetooth-Based Android Smartphone, Inter. J. Wireless \& Mobile Networks (IJWMN). 5: 65-72. 